\title{
Failure Mechanism Analysis of Electromagnetic Brake Iron Core Damping
}

\author{
Xiao Liang*, Xiaochang Liu and Facai Ren \\ Shanghai Institute of Special Equipment Inspection and Technical Research, Shanghai 200062, P.R. China; \\ *Correspond Author
}

\begin{abstract}
Elevator accidents occur frequently, brake function failure is one of the main factors. If the brake function fails, it will cause the elevator to run out of control. Therefore, the effectiveness of the brake function is closely related to the safety of the occupants. The electromagnet is the most critical components of elevator braking system. In this paper, combined with an electromagnetic brake iron core damping case, by taking various analytical methods, such as external assessment, chemical composition analysis, and microstructure, analysis the cause of the electromagnetic brake iron core damping. Based on the analysis results, it can be inferred that brake electromagnet brake iron core damping faults is related to iron core anomalies adhesive wear. Meanwhile, as the iron core is an abnormal ferromagnetic material (DT4), this will increase the iron core on the adsorption of ferromagnetic chips.
\end{abstract}

Keywords- elevator accidents; brake function; electromagnet; Failure; iron core damping; ferromagnetic material

\section{INTRODUCTION}

In recent years, elevator accidents occur frequently, brake function failure is one of the main factors. The importance of the brake is like car braking system, its safety and reliability directly affect the staff's life safety and production capacity. If the brake function fails, it will cause the elevator to run out of control, at this time the car will take an upward or downward movement under the action of weight and gravity, the operation of the elevator exist serious security risks, it is the direct cause of shear and crush injury. Therefore, the effectiveness of the brake function is closely related to the safety of the occupants.

\section{ELEVATOR BRAKE WORKING PRINCIPLE}

Brake working condition including band-type brake and loose brake, mainly be controlled by the brake electromagnet excitation coil state (get or lose electricity).As shown in Fig. 1, when the electromagnetic excitation coil is energized, the magnetic iron core is magnetized rapidly under the action of the current magnetic field. Thus, the brake arm is driven to overcome the force of the brake spring, and the brake shoe is completely detached from the brake wheel. When the electromagnetic coil lost electricity, between electromagnetic iron core is not attractive, brake spring is released, the brake shoe is uniformly pressed on the brake wheel under the action of the brake spring, keep the brake wheel tight.

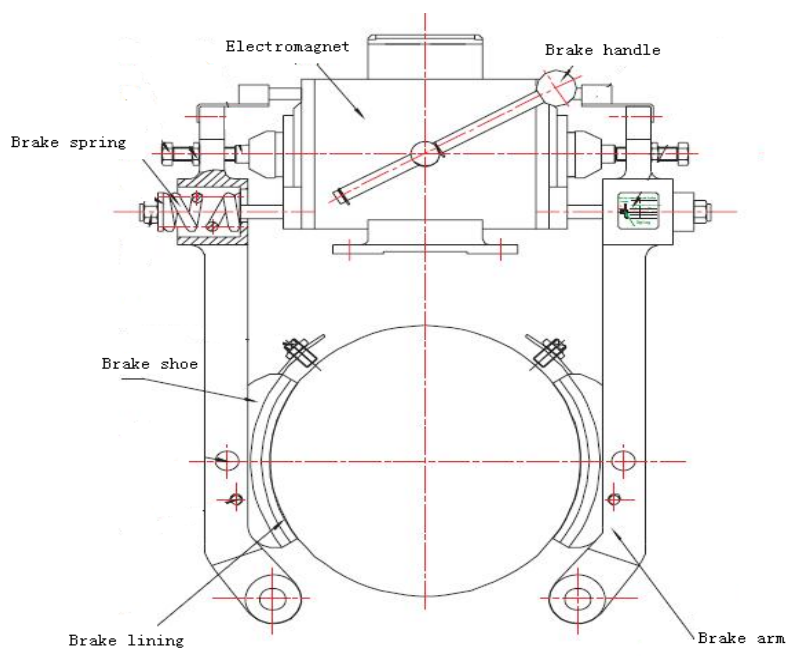

FIGUREI. ELEVATOR BRAKE STRUCTURE

III. ELECTROMAGNET STRUCTURE

Elevator braking system is generally composed of electromechanical brake (friction).The main components are electromagnet, brake springs, brake wheel and brake lining, etc. Among them, the electromagnet is the most critical components, which is shown in Fig.2.An electromagnet is a kind of electrical equipment that converts electromagnetic energy into mechanical energy. Electromagnet structure is relatively simple, which is composed of an excitation coil and a magnetic circuit (iron core, guide ring), etc.. in

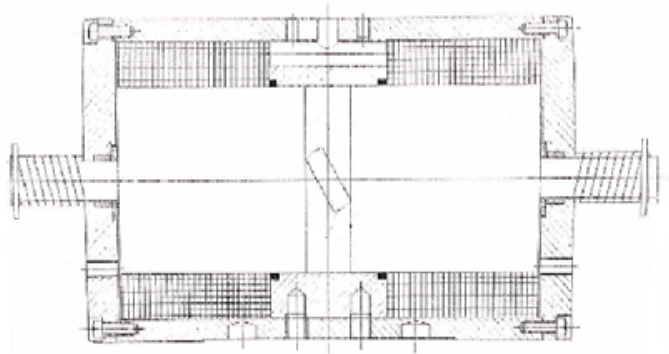

FIGUREII. ELECTROMAGNET STRUCTURE

\section{ELECTROMAGNETIC BRAKE IRON CORE DAMPING CASE}

In the working process of electromagnet brake iron core occurred damping failure one day, causing the elevator to run 
out of control and passengers were injured in the car. Through the dismantling of the accident elevator brake, and observe the damage, the accident investigation team initially determined this elevator accident summit related to electromagnetic brake iron core damping problems. To further confirm the cause of the electromagnetic brake iron core damping, the accident investigation team takes various analytical methods, such as external assessment, chemical composition analysis, and microstructure.

\section{A. External Assessment}

Two iron core shape and damage morphology are basically the same. The outer diameter of the iron core body is about $95 \mathrm{~mm}$. One end of the iron core body is matched with the magnetic guide sleeve, and the other end is provided with a supporting shaft. In the two iron core and the magnetic cover (ring) to match the segment has obvious wear phenomenon, its matching segment traces width of $22.2 \mathrm{~mm} \sim 23.2 \mathrm{~mm}$. The uneven distribution of the longitudinal furrow wear section width is about $17.5 \mathrm{~mm} \sim 18.0 \mathrm{~mm}$.Fig. 3 shows that local surface adhesion with wear debris.

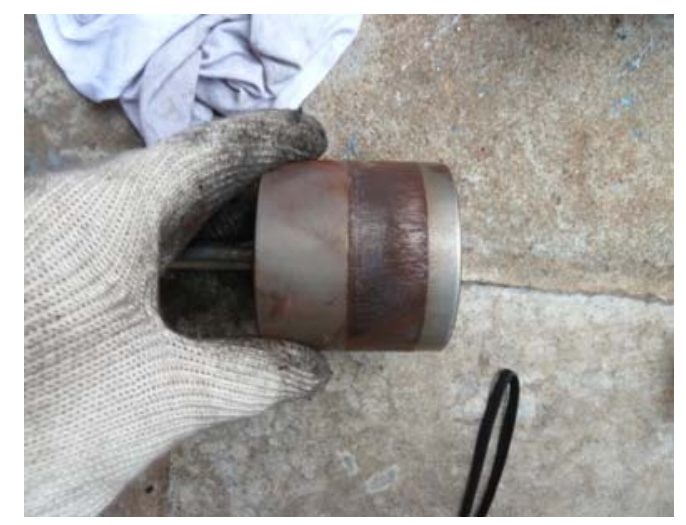

FIGUREIII. ELECTROMAGNETIC BRAKE IRON CORE ADHESION WITH WEAR DEBRIS

\section{B. Scanning Electron Microscopy (sem) Analysis}

Take some wear area under the electron microscope analysis, the results are shown in Fig.4.The area under the macroscopic morphology can be seen along the direction of movement parallel to the broken pits. Higher magnification, we can see the direction of movement along the direction and strain phenomenon. Local visible adhesion cracking, strain morphology. Also visible with foreign objects embedded in rheological morphology.
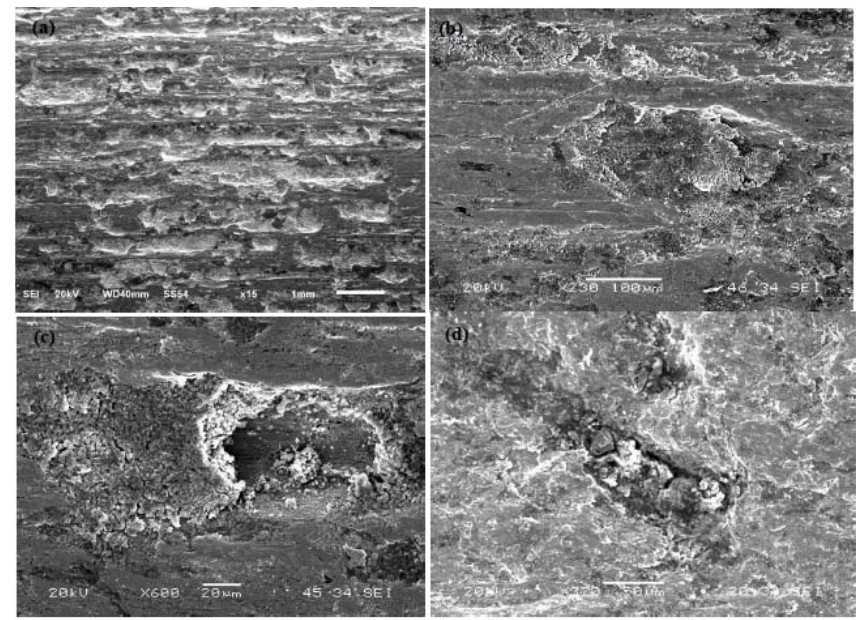

FIGUREIV. WEAR AREA LOW MAGNIFICATION

(SEI);(B)RHEOLOGICAL AND SURFACE STRAIN MORPHOLOGY (SEI);(C)ADHESIVE TENSILE MORPHOLOGY (SEI);(D)LOCAL EMBEDDED SQUEEZE MORPHOLOGY (SEI)

\section{Metallographic Analysis and X - ray Energy Spectrum Analysis}

Metallographic analysis was performed on the cross section of the wear zone. As shown in Fig.5 and Fig.6, we can see that the wear surface concave shape change in this section, rheological depth of $0.024 \mathrm{~mm}$, the matrix structure: ferrite + small amount of pearlite. It can be seen that the shape of the folded rheological fracture is $0.08 \mathrm{~mm}$. The distribution of gray oxide in the cracks shows that the surface oxidation is caused by extrusion rheology.

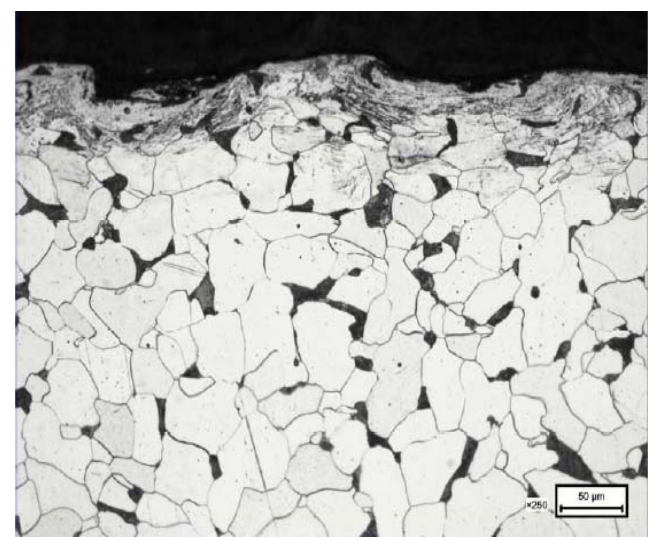

FIGUREV. MICROSTRUCTURE OF THE SURFACE OF THE DAMAGED CROSS SECTION 


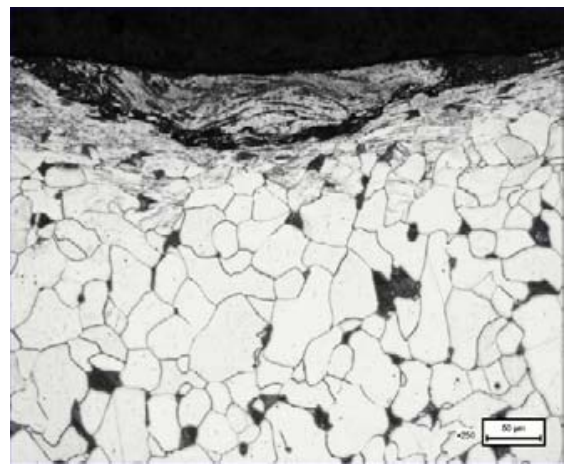

FIGUREVI. THE SURFACE MORPHOLOGY OF THE WORN SURFACE

D. Chemical Analysis

Sampling in the plunger matrix for chemical analysis, the results are as follows in Tabel1:

By chemical analysis and magnetic properties test results show that the failure of brake piston material does not meet the relevant technical requirements of DT4 (GB/T 6983-2008).

\section{CONCLUSIONS}

Based on the above analysis results can be inferred,brake electromagnet brake iron core damping faults is related to iron core anomalies adhesive wear.Meanwhile,as the iron core is an abnormal ferromagnetic material (DT4),this will increase the iron core on the adsorption of ferromagnetic chips.It is bound to increase the probability of the occurrence of abnormal adhesive wear, which is caused by the increase of the relative hardness of the brake bar and the relative high hardness.

\section{REFERENCES}

[1] M. Kumbhar, A. Walavalkar, Magnetostatic analysis and power optimization ofelectric release brake, IEEE International Conference on Magnetics, Machines\& Drives (AICERA-2014 iCMMD) (2014).

[2] R.J. Farris, M. Goldfarb, Design of a multidisc electromechanical brake,IEEE/ASME Trans. Mechatron. 16 (6) (2011) 985-993.

[3] Y.P. Yang, H.C. Lin, C.T. Lu, Design and integration of power wheels with rimmotors for a powered wheelchair, 2011 Int. Conf. Appl. Supercond. Electro-magn. Devices, ASEMD vol. 6 (no. November) (2011) 154-157.

[4] Coey JMD. Hard magnetic materials: a perspective. IEEE Trans Magn. 201l: 47(21): 4671.

TABLE I. THE CHEMICAL ANALYSIS RESULTS

\begin{tabular}{|c|c|c|c|c|c|c|c|c|c|}
\hline Element & $\mathrm{C}$ & $\mathrm{S}$ & $\mathrm{Si}$ & $\mathrm{Mn}$ & $\mathrm{P}$ & $\mathrm{Cr}$ & $\mathrm{Ni}$ & $\mathrm{Al}$ & $\mathrm{Cu}$ \\
\hline Plunger & 0.096 & 0.005 & 0.20 & 0.48 & 0.016 & 0.031 & 0.018 & 0.032 & 0.030 \\
\hline $\begin{array}{c}\text { DT4 } \\
\text { (GB/T6983-2008) }\end{array}$ & $\begin{array}{r}\leqq \\
0.010\end{array}$ & $\begin{array}{r}\leqq \\
0.010\end{array}$ & $\begin{array}{r}\leqq \\
0.10\end{array}$ & $\begin{array}{r}\leqq \\
0.25\end{array}$ & $\begin{array}{r}\leqq \\
0.015\end{array}$ & $0.10 \leqq$ & 0.05 & $\begin{array}{l}0.20 \sim \\
0.80\end{array}$ & 0.05 \\
\hline
\end{tabular}

